\title{
Sinfonia inacabada da habitação coletiva: lições a partir do PREVI para uma arquitetura de possibilidades
}

The unfinished symphony of collective housing: lessons from PREVI towards an architecture of possibilities

\section{Raquel Regina Martini Paula Barros Sílvia Aparecida Mikami Gonçalves Pina}

\section{Resumo

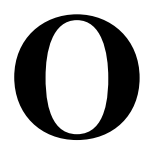

s esforços pela busca de uma maior sustentabilidade nas cidades inspiram os projetos de habitação coletiva como importante perspectiva para devolver caraterística mais humanizadora para o habitar urbano. Este trabalho discute um recorte específico no sentido de intermediar e apoiar as decisões estruturantes do projeto arquitetônico e urbanístico que considere a possibilidade de modificações como parte do processo de projeto e do programa habitacional. O trabalho tem por objetivo obter derivações conceituais para análise, reflexão e realização projetual relacionadas à capacidade adaptativa da habitação como possível agregadora de valor multidimensional para os moradores. A partir dos fundamentos teórico-conceituais relacionados, buscou-se identificar exemplar de habitação coletiva representativo para análise, selecionando-se o Proyecto Experimental de Vivienda-PREVI em Lima, Peru, pela sua importância e impacto. O estudo evidenciou alguns dos enfoques e suscitou outros conceitos relevantes para o processo de projeto. Apresenta-se uma análise do estudo de caso e o aprimoramento da base teóricoconceitual de potencial humanizador e de sustentabilidade socioambiental. O estudo permite o refinamento conceitual vinculado ao projeto da habitação coletiva com vistas à geração de valor multidimensional para o habitar humanizador e mais sustentável.

Palavras-chave: Habitação coletiva. Capacidade adaptativa. PREVI. Diversidade. Flexibilidade. Processos participativos.

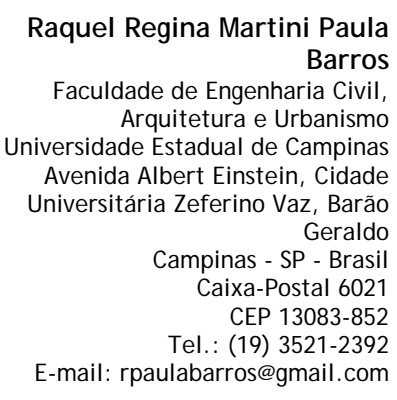

Sílvia Aparecida Mikami Gonçalves Pina Departamento de Arquitetura e Construção, Faculdade de Engenharia Civil, Arquitetura e Urbanismo Universidade Estadual de Campinas E-mail: smikami@fec.unicamp.br

Recebido em 04/06/12 Aceito em 27/08/12

\section{Abstract}

Efforts towards more sustainable cities inspire collective housing design as an important perspective for the recovery of a humanizing characteristic of city living. This paper discusses a specific approach for the intermediation and support of architectural and urban design decisions, involving the possibility of change as part of the design process and housing program. This study aims to obtain conceptual derivations for design analysis, reflection and practice related to the adaptive and flexible capacity of collective housing with a view to aggregating multidimensional value to its users. Founded on a knowledge base with humanizing potential, a search was conducted to find exemplary collective housing design projects. The Proyecto Experimental de Vivienda-PREVI in Lima, Peru was selected for analysis due to its impact and representativeness. The study highlights, as well as inspires relevant design concepts for the improvement of the design process. This paper presents the case study and the matching of approaches of humanizing and socio-environmental sustainability potential. This study allows a conceptual improvement regarding collective housing design aimed at generating multidimensional value for more humanizing and sustainable housing.

Keywords: Collective housing. Adaptable capacity. PREVI. Diversity. Flexibility. Participation processes. 


\section{Introdução}

O projeto da habitação coletiva coloca-se como importante perspectiva para o habitar na busca por maior sustentabilidade urbana. Seu programa abrange desde políticas integradoras das ações sobre o uso do solo, mobilidade e saneamento ambiental, assegurando o direito à cidade, até a viabilidade, eficiência e qualidade das soluções habitacionais em si (PINA, 2008). Requer também a consideração dos processos adaptativos e procedimentos participativos para incentivar uma apropriação espacial positiva por uma diversidade de pessoas, em diversos níveis de renda e fases da vida. Em meio à complexidade dos fatores envolvidos, este trabalho apresenta um recorte específico no sentido de intermediar e apoiar as decisões estruturantes do projeto arquitetônico e urbanístico que considere a possibilidade de modificações como parte do processo de projeto e do programa habitacional.

Mecanismos de segregação espacial transformam o espaço urbano da convivência sadia e espontânea no espaço do medo e da insegurança nas grandes cidades, contribuindo para dificultar o alcance da necessária equidade social e a resiliência das cidades. Autores como Hall (2006) e Bauman (2009) reconhecem a relação entre o crescente individualismo na sociedade capitalista ocidental e a perda da identificação das pessoas com o lugar em que moram. Contudo, Fadda e Jirón (2001) ressaltam a importância daquilo que emana das relações sociais possibilitadas pelos espaços como as distintas percepções e expectativas de desempenho social. Daí a importância de compreender-se a qualidade de vida em termos dos fatores que proporcionem uma vida melhor na perspectiva do ambiente urbano. É preciso que o entendimento dos problemas ambientais vá além do entorno físico, incorporando as pessoas, sua história e realidade de condições sociais, culturais e de vida, ou seja, dos territórios em que vivem, identificam-se e habitam.

Desde longa data reconhece-se que o problema da habitação social não se limita à simples oferta da casa própria como questão meramente quantitativa, muito embora o direcionamento das iniciativas públicas para o setor no Brasil parece operar nessa perspectiva simplista. Bruna (2010) refere-se à oportunidade perdida, ao longo de décadas de produção pública iniciada ainda nos anos 30, de estabelecer-se uma política sistemática e organizada de industrialização da construção. Também se refere ao congelamento das fórmulas repetitivas de implantação urbanística e arquitetura dos conjuntos altamente empobrecedoras da cidade, bem como ao desprezo da crítica arquitetônica brasileira sobre parte das realizações, possivelmente vinculado a posturas ideológicas. Aquele congelamento de fórmulas bem como a falta de aprofundamento da crítica arquitetônica sobre os projetos resultantes afloram também nos resultados de premiações de projetos de habitação coletiva no Estado de São Paulo (BARROS; PINA, 2010; 2011). Muitos desses projetos falham por não responderem plenamente a questões ambientais, socioculturais e psicológicas, sobretudo pela desconsideração de condicionantes que norteiam princípios da sustentabilidade socioambiental e que deveriam, em colaboração, permear o projeto urbano-arquitetônico a partir do entendimento das pessoas e do lugar.

Observa-se uma tendência latente em modificar o ambiente habitacional. Lerup (1977) nega o ajuste perfeito do projeto do ambiente construído com as pessoas e alerta a importância em considerarem-se as ações das pessoas no ambiente que as abriga como processo interativo, dinâmico e natural. Apesar da tendência de não se relacionar de modo direto ao nível de renda, a incidência de intervenções pós-ocupação por iniciativa da população de baixa renda em seu ambiente habitacional tem-se mostrado bastante significativa há décadas (ANDRADE; DUARTE, 1998; KOWALTOWSKI; PINA, 1995). A alta demanda e a instabilidade nos modos de vida dessa população compõem o contexto das intervenções no Brasil, que ocorrem tanto na esfera do assentamento informal quanto na do formalmente projetado. O potencial de um processo de mudança na dinâmica de usos, acompanhado do aumento gradual da capacidade financeira das famílias, parece raramente considerado no projeto habitacional.

As intervenções pós-ocupação espontâneas, que não contam com diretrizes de projeto e assessoria técnica profissional, podem gerar consequências negativas ao longo dos anos, incluindo o desperdício material e energético, o comprometimento da permeabilidade do solo e da qualidade ambiental e estrutural das moradias, além de efeitos nocivos à qualidade de vida dos moradores. Elas podem ser motivadas pela ausência de qualidade ou inadequação do ambiente construído, ocasionada por falhas de projeto, incluindo, entre outros, o não detalhamento, falhas de execução e emprego de materiais de qualidade insuficiente. Deficiências frequentes aliam-se à falta de envolvimento dos moradores no processo de projeto, assim como a ausência de programas de gestão de uso e manutenção dos espaços. Processos adaptativos espontâneos em 
empreendimentos habitacionais projetados apresentam similaridades àqueles que ocorrem na moradia autoconstruída (PINA et al., 2005; ANDRADE; DUARTE, 1998), sobretudo na meta de ampliação da área da moradia. Estudos sobre a moradia autoconstruída paulista (TASCHNER; MAUTNER, 1982; LEMOS; SAMPAIO, 1976) apontam ainda a restrição de opções na escolha de materiais e de inovação construtiva ou formal, dada a escassez de recursos, o uso de mão de obra familiar e a limitada disponibilidade de materiais.

Por outro lado, alguns projetos já consolidados revelam a complexidade do tema ao permitirem intepretações diversas e o afloramento dos aspectos positivos do empenho e da cooperação na adaptação da própria moradia e seu entorno, em contraponto aos conjuntos habitacionais de caráter rígido e indistinto, em larga escala e mal localizados. Um exemplo distinto de iniciativa dos próprios moradores para o melhor ajuste a suas necessidades e aspirações em conjuntos projetados pode ser observado no Quartiers Modernes Frugès (QMF), em Pessac, na França, projetado por Le Corbusier e entregue à população em 1926. Ainda que falhas construtivas tenham motivado intervenções logo após sua ocupação, Boudon (1972) constatou que o projeto de estética purista serviu de base para modificações diversas. Foram comuns a eliminação dos pilotis, o surgimento de coberturas em duas águas sobre as lajes planas e terraços, o fechamento parcial dos extensos vãos das janelas horizontais ou sua substituição por esquadrias tradicionais com venezianas e o acréscimo de ornamentação nas fachadas. Sobre a obra, Lefèbvre (1972) considera que os preceitos ideológicos e teóricos de Le Corbusier foram superados em face da realidade e que o projeto, na prática, teria sido mais hesitante, flexível e vital que sua teoria. Recentemente, parte dos moradores deu-se conta da importância arquitetônica e histórica do conjunto e do seu potencial turístico, somando esforços na reconstituição do projeto original, visando à candidatura do bairro à lista de patrimônio mundial da Unesco, em análise (CANDIDATURE..., 2012).

Ante tal fenômeno, estuda-se o projeto original e as intervenções ocorridas no Proyecto Experimental de Vivienda (PREVI), em Lima, Peru. Abordagens conceituais relacionadas ao tema da humanização e da sustentabilidade, com enfoque no recorte proposto, são relacionadas ao projeto investigado e permitem o aprimoramento da base teórico-conceitual de potencial humanizador e de sustentabilidade socioambiental.

\section{Abordagens relacionadas à adaptação gradativa}

Temas entrelaçados configuram possíveis contribuições para o projeto que considera a possibilidade de modificações no ambiente construído. Schneider e Till (2007) identificam três momentos históricos na agenda da habitação coletiva flexível contemporânea, sobretudo no contexto europeu e, posteriormente, no norteamericano. São eles: a modernidade e a habitação mínima, refletindo inicialmente a alta demanda por habitação para as classes trabalhadoras no período pós-Primeira Guerra em densidade e escala sem precedentes, relacionada à flexibilidade tanto pelas reduzidas dimensões bem como pelos novos modos de vida a serem proporcionados pela tecnologia mecanizada; a industrialização da habitação valendo-se da padronização e eficiência, relacionada à flexibilidade no sentido da possibilidade de diferentes arranjos dos componentes construtivos; e, a partir dos anos de 1960, a valorização da participação e possibilidades de escolha por parte dos moradores. Em todos os episódios, o conceito de flexibilidade esteve presente como meio para atingirem-se outras demandas e, guardadas as diferenças contextuais, permanecem na agenda da habitação contemporânea.

Especialmente para o contexto habitacional de recursos mínimos, alta demanda e urgência, onde a incerteza é modo de vida, Hamdi (1991) propõe o entendimento da prática projetual da habitação sob os temas da participação, flexibilidade e empoderamento para a promoção de uma arquitetura de cooperação e desenvolvimento incremental. Tal entendimento conduziria a um processo de projeto de empoderamento, no sentido de capacitar o arquiteto, bem como as pessoas em suas próprias moradias e territórios, para o alcance de uma resposta integrada de projeto e como meio efetivo de emancipação pessoal e coletiva. O empoderamento na habitação seria o processo pelo qual se cultivam física e gradualmente as condições que permitam a habitação e vizinhanças de crescer e transformar-se diante das condições do momento. Assim, os arquitetos precisam compreender seu trabalho como parte de um processo vivo, ou seja, ser cultivadores de ambientes, e não fazedores de projetos. A flexibilidade como modo construtivo estaria associada ao imperativo sociopolítico, viabilizando a participação dos moradores no processo de projeto e capacitando-os a transformar sua unidade de habitação em um lar.

Sob o enfoque de tais temas, Hamdi (1991) trata dos olhares distintos, porém em sintonia com as 
obras seminais de N. J. Habraken e de J. Turner, ao expor a oposição entre os paradigmas do provedor e do suporte para a habitação. Os adeptos do paradigma do provedor, dominante na história, seguem linha de pensamento que enquadra terra, trabalho e capital, de modo a encorajar o consumo, e não a satisfação das necessidades humanas. Supostamente, isso criaria empregos, geraria lucros e melhoraria o padrão de vida até dos mais miseráveis. Todavia, os adeptos do paradigma do suporte, inicialmente proposto por Habraken (1999), original de 1961, consideram que o sistema provedor pouco contribui para a melhoria das condições de vida dos mais pobres e que, quando a habitação torna-se uma commodity fornecida por agências paternalistas, não há espaço para o envolvimento no processo em si. O enfoque de Turner (1976) sobre o paradigma do suporte teria menos relação com a estruturação do ambiente físico e mais com sua localização, custo, modalidades de propriedade a locação, segurança e liberdade para mudar-se. Nesse sentido, flexibilidade seria a qualidade por meio da qual se medem as oportunidades disponíveis às pessoas para a autogestão de programas localmente, enquanto, para Habraken (1999), seria a qualidade por meio da qual se mede a capacidade do ambiente físico de ser facilmente modificável, podendo passar por uma série de transformações incrementais a fim de garantir um bom ajuste ao longo do tempo. Um sistema de suporte permitiria que uma moradia fosse passível de execução, alteração e mesmo demolição, independentemente das outras moradias. Oportunidades de projeto de suporte e preenchimento possibilitariam uma variedade infindável de moradias, a renovar-se constantemente. Lyle (1994) propõe o projeto regenerativo para o restabelecimento da conexão entre as pessoas e a natureza no ambiente construído, de modo a manter a integridade dos processos naturais que dão suporte à vida, abordando-os de maneira inter-relacionada, a exemplo de como funcionam na natureza. A proposta toma o ecossistema humano como conceito e adota os princípios relacionados, que se aplicam a um incremento básico inicial e se desenvolvem gradualmente, adquirindo complexidade e coesão com a participação dos usuários ao longo do tempo.

A apreciação da arquitetura por seus usuários, conforme Benedikt (1997; 2008), requer o engajamento com o ambiente construído, e a promoção progressiva da qualidade de vida requer a conciliação de valores éticos, estéticos e econômicos. Para tanto, amplia e adapta a teoria das necessidades ou valores humanos, proposta por Maslow em 1943, para a ação em arquitetura. Os valores se constituiriam em elementos-chave que todo projeto de edificação deveria considerar e, em conjunto, favoreceriam o alcance da liberdade em suas diversas modalidades: de deslocamento, opinião, espaço, flexibilidade, de exclusão e privacidade. Considera-se que o princípio da moradia autônoma ou independente proposto por Habraken (1999) equivale ao alcance do valor da liberdade colocado por Benedikt (2008). Habraken concebe que o sistema de produção em massa da habitação bloqueia a atividade do indivíduomorador e que, para o resgate da relação natural entre ser humano e ambiente, faz-se necessário alcançar uma moradia autônoma ou independente. A construção de uma edificação seria uma identificação relacionada estreitamente ao desejo de possessão, propositadamente frustrado naquele sistema de produção da habitação. O princípio da independência remete também ao conceito de habitação como processo, como ação coletiva da sociedade. Santos e Vogel (1985) observam o caráter de autonomia das relações sociais nos territórios coletivos que permitem a negociação cotidiana de suas regras de uso, ao mesmo tempo compartilhadas e flexíveis.

Barros (2008) propõe a categoria conceitual "senso de urbanidade" para o projeto de habitação coletiva, visando proporcionar a vivacidade urbana, que pressupõe evitar a segregação socioambiental; proporcionar a percepção de um sentido de lugar em sintonia com o entorno a partir da conformação e articulação entre arranjos espaciais e espaços externos resultantes nas escalas da moradia à cidade; e atender às funções psicológicas de orientação e identificação. Consideram-se a sobreposição de relações socioespaciais na trama urbana e a preocupação com o lugar e seu significado, incluindo o conceito de genius loci e a percepção de uma imagem ambiental.

Em meio a exemplares que variam de rígidos a quase indeterminados no que se refere ao grau de controle do arquiteto e de seu projeto sobre as possibilidades formais, técnicas e de uso, Schneider e Till (2007) ressaltam um olhar mais amplo sobre o conceito de flexibilidade, relacionado à inata oportunidade de adaptabilidade, capaz de usos sociais diferentes, independentemente da possibilidade ou não de distintos arranjos espaciais e construtivos. Os argumentos apresentados pelos autores para a habitação mais flexível, mesmo conhecidos, são convincentes: socialmente ele habilita o morador a assumir o controle de sua habitação, quer por fazer escolhas antes da construção definitiva ou durante o ciclo de vida da moradia. Demograficamente, permite ajustar os projetos aos modos de vida e às 
novas configurações familiares. Tecnicamente, pode permitir a incorporação de novas tecnologias e a modernização das antigas, especialmente quanto às instalações prediais.

Neste trabalho, aquele olhar mais amplo sobre o conceito de flexibilidade é tomado como contribuição para uma abordagem comprometida com a capacidade sociocultural de transformação do ambiente construído nas diferentes escalas, da arquitetura à cidade. A habilidade de resposta à dinâmica de usos e das necessidades e expectativas dos moradores atuais e futuros é de particular importância para as camadas pobres da população, que requerem habitação com mescla de usos e de pessoas e em localizações que proporcionem o direito à cidade, de mecanismos de suporte à geração de renda, entre outras. Relevantes estudos de diferentes épocas (COELHO; CABRITA, 2009; TALLEN, 2008; JACOBS, 1961) salientam a importância da diversidade para uma abrangência de aspectos qualitativos, incluindo a segurança e a vivacidade urbana. Adicionalmente, ao investigar a possível aplicação do conceito de resiliência para o sistema socioecológico das cidades, Du Plessis (2012) considera que a interpretação correta do conceito seria a de habilidade de adaptar-se a mudanças, o que, por sua vez, dependeria da diversidade de usos e respostas, a exemplo do funcionamento dos ecossistemas.

As diferentes necessidades humanas de convívio e proteção no ambiente construído refletem a diversidade de pessoas e impactam nas diferentes escalas da moradia à cidade. Barros (2008) propõe conceitos humanizadores a partir de associações entre parâmetros de projeto que demonstram uma conexão direta à vivência humana nos territórios habitacionais. Parâmetros relacionados ao grau de conformação e articulação entre os arranjos espaciais e espaços resultantes podem promover a percepção de um sentido de lugar e o atendimento das funções psicológicas de orientação e identificação, proporcionando a apropriação positiva dos espaços e a acomodação das demandas variadas no tempo.

\section{Busca por projetos adaptativos e flexíveis: o PREVI}

Para Para a seleção do caso de estudo, buscou-se projetos representativos das abordagens e derivações conceituais e com potencialidade de suscitar outros conceitos relevantes de projeto, nos âmbitos nacional e internacional, com a condição de terem sido construídos. O caso do PREVI, em Lima, foi selecionado para investigação por constituir projeto de habitação coletiva já realizado, ocupado e consolidado, e por seu caráter experimental, envolvendo conceitos e modalidades tipológicas variados, com capacidade adaptativa e flexível. Foram feitos levantamentos documentais e de estudos já realizados para melhor compreensão do caso de análise. Para atualização e aprofundamento do estado presente do PREVI, foi realizada visita técnica ao local entre janeiro e fevereiro de 2012. Naquela ocasião, também se realizou visita específica a algumas residências das Quadras 16 e 17, projeto de Alexander e equipe. A percepção dos moradores e sua satisfação relativa aos aspectos socioculturais e ambientais das habitações e dos espaços coletivos foram obtidas por meio de entrevistas semiestruturadas, observações, registros fotográficos e croquis. Através de formulários aplicados obtiveram-se informações sobre: a data em que os moradores mudaram-se para o local; quantos residiam àquela época e quantos moram hoje na casa; a relação de parentesco entre eles e o proprietário do imóvel, entre outras informações.

O PREVI foi objeto de concurso internacional de projetos e teve o intuito de estabelecer as bases para uma nova política pública habitacional local. Os diferentes projetos urbanísticos apresentados e as tipologias habitacionais efetivamente construídas foram objeto de avaliações conduzidas por instituições públicas locais (BARRIONUEVO; JARA; SANTOLALA， 1971; INSTITUTO..., 1979; 1988). Após décadas de ocupação, a importância da proposta arquitetônica e urbanística empreendida tem instigado novas e relevantes pesquisas (TENICELA, 2002; GARCÍAHUIDOBRO; TORRITI; TUGAS, 2008; LUCAS; SALAS; BARRIONUEVO, 2012). 


\begin{tabular}{|c|c|c|}
\hline \multirow{5}{*}{ 帘 } & VIZINHANÇA & $\begin{array}{l}\text { Grupo de moradias; Gradiente privacidade no arranjo } \\
\text { do conjunto }\end{array}$ \\
\hline & SISTEMA VIÁRIO & $\begin{array}{l}\text { Estacionamento coletivo visível a partir moradias; } \\
\text { Estacionamentos pequenos }\end{array}$ \\
\hline & REDE DE CAMINHOS PEDESTRES & Passeio; Simbiose carro-pedestre \\
\hline & EIXO COMUNITÁRIO & Escolas abertas; Jardins coletivos delimitados \\
\hline & INTERIOR DA VIZINHANÇA & $\begin{array}{l}\text { Demarcação entrada coletiva; Espaços abertos uso } \\
\text { múltiplo; Comércio nas esquinas; Caminhos centrípetos }\end{array}$ \\
\hline \multirow{7}{*}{ 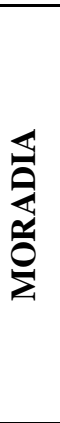 } & ORIENTAÇÃO E FORMA & $\begin{array}{l}\text { Casa estreita e comprida; Parede perimetral; Ventilação } \\
\text { cruzada; Luz natural a partir de duas faces; Pátios que } \\
\text { vivem; Trama de luz e sombra }\end{array}$ \\
\hline & PARTE SOCIAL & Gradiente de intimidade; Localização do banheiro \\
\hline & PARTE FAMILIAR & Circulação na sala de jantar/ estar \\
\hline & ÁREAS PARA DORMIR & $\begin{array}{l}\text { Pessoas idosas no piso térreo; Banheiro de uso } \\
\text { compartimentado }\end{array}$ \\
\hline & ENTRADA E FACHADA & Transição na entrada; Porta frontal recuada \\
\hline & PÁTIOS & Luz natural a partir de pátios em sobrados \\
\hline & PEQUENO COMÉRCIO E ALUGUEL & Espaço para alugar \\
\hline
\end{tabular}

Quadro 1 - Seleção de parâmetros para comunidade e moradia

Fonte: quadro elaboradop a partir de Alexander et al. (1969, p. 55-194).

O estudo de caso em questão analisa a proposta urbanística implementada e também enfoca o grupo de moradias construídas a partir do projeto submetido por Alexander e equipe, fundamentado em uma combinação de 67 patterns formulada especificamente para o PREVI e apresentada em Alexander et al. (1969). Os patterns expressam a percepção de necessidades humanas no ambiente construído e foram aqui considerados como parâmetros projetuais, a exemplo do adotado em Barros (2008). Assim, o caráter propositivo dos patterns enfatiza essa interpretação, como elementos cuja variação de valor contribui e orienta a solução de um problema no todo, sem lhe modificar a natureza. Uma seleção feita a partir daquela combinação de parâmetros para o PREVI é apresentada no Quadro 1 e foi utilizada para a avaliação projetual. Verifica-se seu potencial de contribuição para o aprimoramento da base teórico-conceitual em questão a partir da verificação de sua influência na proposta urbanística do PREVI e de sua relevância para os modos de vida dos moradores das habitações das Quadras 16 e 17 após 35 anos de ocupação. A avaliação também se pauta nas abordagens relacionadas à adaptação gradativa e na leitura, observação e percepção dos pesquisadores.

\section{Concurso internacional para o Proyecto Experimental de Vivienda - PREVI}

Em 1966, o governo do Peru formulou um projeto experimental, a ser cofinanciado pelo Programa das Nações Unidas para o Desenvolvimento (PNUD), para oportunidade de novos conceitos e técnicas com o intuito de nutrir uma nova política pública na área da habitação no país. O arquiteto inglês Peter Land foi convidado a coordenar a iniciativa do Proyecto Piloto 1-PP1, objeto de concurso aberto aos arquitetos peruanos e a 13 equipes convidadas de arquitetos estrangeiros em 1969. O PP1 abrigaria uma comunidade de 1.500 moradias em área de 40 ha na periferia de Lima, cerca de $8 \mathrm{~km}$ ao norte da cidade. As propostas estariam livres dos regulamentos e normas nacionais para projeto e construção, a fim de permitir a investigação ampla e o desenvolvimento de novos conceitos (INSTITUTO..., 1979). Lucas, Salas e Barrionuevo (2012) esclarecem que, enquanto a proposta de lotes e serviços do Proyecto Piloto 3-PP3 dirigia-se aos níveis de pobreza extrema, o PP1 dirigia-se sobretudo à população de baixa renda com certa capacidade aquisitiva. A partir dos dados existentes (CANDILIS; JOSIC; WOODS, 1970; INISTITUTO..., 1979), apresenta-se uma síntese dos fatores e requisitos programáticos mais relevantes do edital e relacionados aos fatores ambientais, urbanísticos, de desenho urbano e arquitetura do concurso.

No edital do concurso, os fatores ambientais destacados incluíram dados sobre as distintas zonas de solo que compõem o terreno natural e cargas unitárias para fins de cálculo estrutural; a topografia praticamente plana; a capacidade do lençol freático para o pleno abastecimento do bairro e disponibilidade de descarga no mar via grande emissor existente. Outros condicionantes 
locais decorrem da latitude $\left(12^{\circ} 4^{\prime}\right)$, da altitude (137 m) e da localização de Lima, entre o mar e os Andes, ou seja, a alta luminosidade natural; precipitações quase nulas, alta umidade do ar, entre $60 \%$ e $100 \%$; verão com dias quentes, todavia agradáveis no início da noite; e brisas leves, úmidas e frias vindas do mar ao longo da tarde, predominantemente do sudoeste. A tradição local do cultivo da vegetação em muros e vasos, os jardins de água e os pátios mouriscos foram apontados como adequados à necessidade de contenção de gastos com irrigação. O arranjo dos espaços intramuros deveria permitir aos próprios moradores o desenvolvimento de jardins a partir do pátio estruturante. Atentava-se também para a necessidade de prevenção de ruídos vindos, sobretudo, da rodovia próxima, a Panamericana Norte.

A proposta urbanística deveria estabelecer a relação com os serviços comunitários e assentamentos do entorno e infraestrutura existente. Conforme o Plano de Desenvolvimento Urbano Metropolitano àquela época, o terreno situava-se em nova área de desenvolvimento acelerado da cidade, em cinturão residencial próximo à zona industrial e servido por nova rede viária local em comunicação com a rodovia Panamericana Norte. O projeto deveria incluir creches, escolas primárias, escolas de ensino médio, centro esportivo, centro comunitário, comércio, serviços institucionais, equipamentos comunitários, praças e espaços abertos. A proposta deveria explicitar a relação entre veículos, pedestres, comércio, etc. Previam-se vagas de automóveis para cerca de $50 \%$ das famílias, abrigadas em estacionamentos coletivos, sendo desejável a separação entre pedestres e automóveis, com prioridade para pedestres. O alto custo das vias pavimentadas determinava que fossem mantidas ao estritamente necessário.

Diferentes faixas de custo deveriam ser previstas para o projeto das habitações, de acordo com o financiamento entre $20 \%$ e $25 \%$ do rendimento mensal das famílias. O desenho urbano previa espaços abertos de uso múltiplo e de dimensões abreviadas, sugerindo a observação dos elementos tradicionais e compactos dos espaços abertos das cidades peruanas, incluindo a praça, o átrio e o passeio, caracterizados pelo uso de pedestres. A observação cuidadosa acerca dos usos e tradições locais aliava-se também à outra questão programática como contraponto ao paradigma moderno: a ênfase na exploração e no desenvolvimento de técnicas para a habitação compacta de baixa altura em arranjo denso com explícita objeção à tipologia de edifícios de múltiplos pavimentos.
As moradias deveriam ser concebidas estruturalmente para evolução e distribuir-se inicialmente da seguinte maneira: $40 \%$ para casais com 2 crianças, $40 \%$ com 4 crianças e $20 \%$ com 6 crianças, sendo que $25 \%$ do total das moradias deveriam ser incompletas, prevendo o desenvolvimento futuro pelos próprios moradores, mas com assistência técnica profissional e construídas por empreiteira. O projeto poderia prever o uso múltiplo para as áreas de estar, jantar e cozinha, geralmente separadas no Peru. Deveria também evitar longos corredores e prever o uso das áreas de cobertura como espaços abertos. Os lotes deveriam ter entre 80 e $150 \mathrm{~m}^{2}$, e a área construída prevista era de 60 a $120 \mathrm{~m}^{2}$ e deveria ser delimitada por muro de 2,20 m de altura, em combinação com as paredes das unidades.

Três prêmios foram concedidos para cada grupo, nacional e internacional. O resultado do concurso apontou como vencedores internacionais Atelier 5 (Suíça), Herbert Ohl (Alemanha) e Kikutaki e equipe (Japão). Os três peruanos foram: Mazzarri e Llanos e as equipes de Chaparro e de Crousse (CANDILIS; JOSIC; WOODS, 1970). Há registro de significativo impasse ocorrido na ocasião do julgamento do concurso por conta da classificação da proposta de Alexander et al., em $4^{\circ}$ lugar. Uma parte dos membros do juri registrou manifesto, visto considerar aquela como a melhor proposta.

Após novas circunstâncias políticas e crises institucionais, o terremoto severo em Lima em 1970 e a alta qualidade das propostas resultantes do concurso, a iniciativa foi redimensionada para um terço da área original em um novo projeto conduzido por Peter Land para aproximadamente 500 habitações. A construção deu-se por meio de pequenos grupos a partir de uma seleção dos diferentes projetos do concurso, contando também com a assistência técnica de especialistas em engenharia sísmica (LAND, 2008). A opção levada a cabo constitui uma síntese dos critérios considerados mais interessantes dos diferentes projetos (Figura 3). A análise comparativa entre eles indica uma densidade média de 36 a 40 unidades/ha e a predominância da agregação das habitações em fita, que configurava $70 \%$ dos projetos inscritos. Nas habitações, a circulação vertical foi prevista em $100 \%$ das propostas e, em $70 \%$ dos casos, a circulação horizontal integra-se à área social (INSTITUTO..., 1979).

\section{Proposta global de Alexander e equipe}

Antes da apresentação do estudo de caso em si, é pertinente salientar a proposta da equipe norteamericana para a área designada pelo concurso, com densidade bruta de 43 moradias/ha, 
totalizando 1.726 moradias. Alexander et al. (1969) explicaram que o desenho da implantação era aproximado (Figura 1), visto que um processo de escolha permitiria aos moradores definir a forma e a extensão da habitação e dos lotes com maior precisão. $\mathrm{O}$ sistema construtivo permitiria a alteração das paredes internas e instalações. O processo de escolha os levaria a hierarquizar as partes da habitação segundo suas necessidades particulares, bem como em relação a sua capacidade financeira prevista para o período de financiamento. $\mathrm{Na}$ sequência, um processo de combinação a ser conduzido por um arquiteto compatibilizaria as escolhas dos moradores. Vizinhanças ou cada grupo de moradias teriam de 30 a 70 habitações e seriam envolvidas por ruas levemente rebaixadas, que alimentariam os pequenos bolsões de estacionamento coletivo. As vizinhanças possibilitariam a apropriação dos espaços por seus moradores, dando-lhes ambiência própria, sendo o formato e a circulação em cada vizinhança únicos e relacionados a sua localização no conjunto. A partir dessas vizinhanças, o sítio conteria três configurações sobrepostas - sistema viário, rede de caminhos de pedestres e eixo comunitário, constituindo os elementos estruturantes propostos pela equipe e reunidos em "Parâmetros para a comunidade”. A Figura 1 representa trecho da implantação do projeto original da referida equipe.

Na escala das moradias, o lote teria 5,2 m de largura e entre $13 \mathrm{~m}$ e $27 \mathrm{~m}$ de comprimento. A habitação seria assobradada e constituída por uma alternância de ambientes e pátios ao longo de sua extensão, conectados por varandas de $2 \mathrm{~m}$ de profundidade (Figura 2). Essa alternância proporcionaria luz e ar naturais para cada ambiente, dotando-lhes de uma sensação de amplidão. Os dois pátios seriam alinhados na direção da brisa predominante (sul), canalizando o ar fresco no verão. No inverno, estes poderiam ser cobertos por uma lona retrátil translúcida controlável no piso superior. O térreo conteria duas partes, sendo a parte social definida pelo pátio frontal e sala social para o tratamento adequado às visitas, refletindo o uso vivenciado no local; a parte familiar caracterizar-se-ia pela sala de jantar e de estar, seguida de um segundo pátio multiúso e cozinha, conectada ao quintal. No piso superior o quarto do casal dividiria a habitação em dois extremos de alcovas para os filhos. Todas as moradias poderiam acomodar acréscimos para abrigar parentes mais idosos, com banheiro no térreo, e os lotes com duas frentes ou de esquina poderiam também abrigar pequeno comércio ou espaço para aluguel. Todas as moradias seriam caracterizadas por entradas demarcadas por porta frontal recuada e banco externo, e no piso superior, por uma galeria ou mirador frontal, também refletindo a característica local de observação do movimento da rua a partir do ambiente interno e protegido da casa. A Figura 2 representa a habitação original.

A equipe propunha o uso de blocos intertravados de concreto moldado in loco a partir de mistura seca e sem o uso de rejunte, dotados de cavidades para as instalações, denominados EDI-Thermomod e patenteados pela equipe. O bloco já havia sido adotado na construção de habitações no México e no sudeste dos EUA, inclusive com sucesso no quesito resistência sísmica. A adaptabilidade dos espaços era possível através da alteração de posição das paredes internas e instalações dentro do sistema construtivo proposto. O sistema seria pré-moldado no local, de fácil manuseio e baixo custo, consistindo de vigas e pilares compostos de placas em bambu preenchidas com poliuretano.

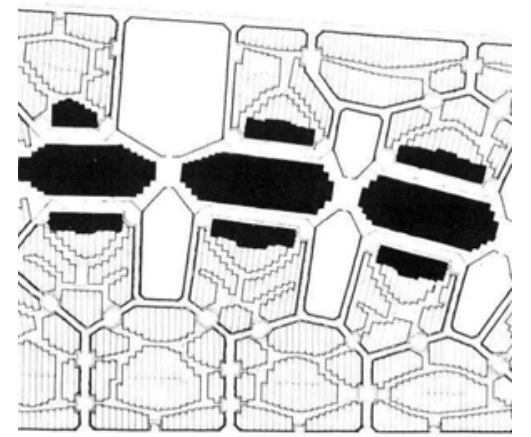

(a) lotes residenciais de maior exposição a pedestres e atividades na alameda central

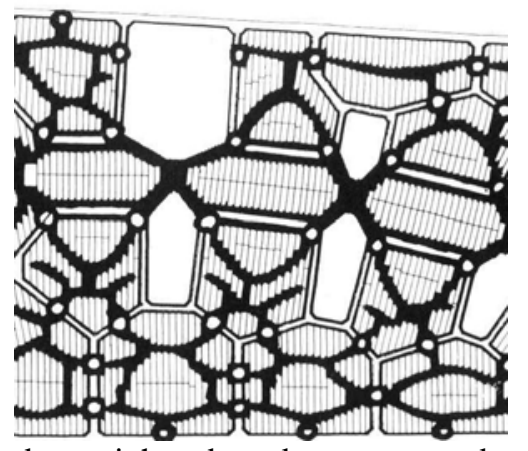

(b) rede de caminhos de pedestres cruzando sistema viário, em simbiose

Figura 1 - Trecho de implantação proposto pela equipe norte-americana

Fonte: adaptado de Alexander et al. (1969, p. 60, p. 79). 

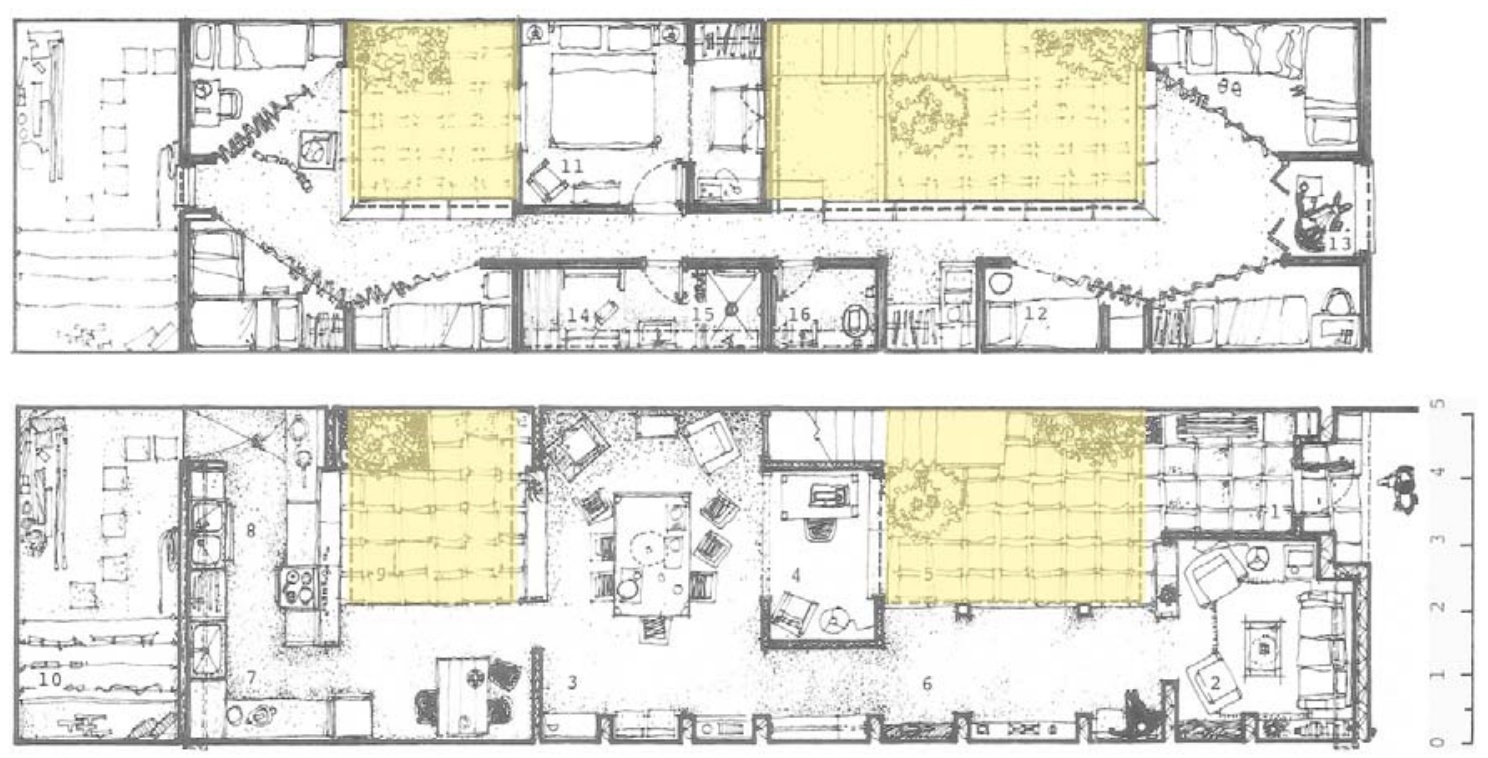

Figura 2 - Plantas-tipo térreo e superior

Fonte: adaptado de Alexander et al. (1969, p. 8, 9, 120).

\section{Implementação do Proyecto Experimental de Vivienda - PREVI}

O desenho urbano beneficiou-se da topografia plana, que garantiu a acessibilidade dos percursos e acessos às moradias, equipamentos e serviços. A configuração de espaços abertos de pequenas dimensões pelo arranjo das habitações, aliada à presença da vegetação, propiciam um microclima agradável, que colabora para a manutenção da umidade do ar e minimiza os efeitos da iluminação natural intensa no verão. Morros de adobe foram utilizados na divisa com a rodovia Panamericana Norte como estratégia para barrar a maior fonte de ruídos no local. Posteriormente, esses morros foram eliminados para permitir mais vagas para os automóveis individuais, conforme constatado na visita técnica. Os bolsões de estacionamento coletivo estrategicamente localizados para a minimização das distâncias a serem percorridas a pé até as moradias são insuficientes, visto o aumento imprevisto de demanda por vagas. A Figura 3 representa a implantação do conjunto, que foi entregue aos moradores em etapas, concluídas em 1978.

A análise comparativa entre as propostas submetidas indica uma densidade média de 36 a 40 unidades/ha e a predominância da agregação das habitações em fita, configurando $70 \%$ dos projetos inscritos. A circulação vertical foi prevista em $100 \%$ das propostas. Na sequência, a Figura 4 apresenta alguns dos espaços abertos do PREVI em suas diferentes escalas, do público ao coletivo. Nela, identificam-se respectivamente os seguintes parâmetros:

(a) passeio (alameda central);

(b) escolas abertas (creches, colégio Jorge

Basadre e respectivos espaços abertos);

(c) caminhos centrípetos (passeios que se alargam, criando ambiente de estar); e

(d) jardins coletivos delimitados nas diferentes vizinhanças, de caráter semiprivado.

A proposta de Alexander et al. (1969) para o concurso, de fato, influenciou o projeto implementado do PREVI, sobretudo:

(a) na configuração espacial das quadras em pequenos grupos de moradias que possibilitam diferentes graus de exposição para as moradias no arranjo do conjunto, conformando caminhos de pedestres, pequenas praças e entradas coletivas;

(b) na rede hierarquizada de caminhos de pedestres, culminando na alameda central, que, por sua vez, congrega usos educacionais, lazer, comércio e serviços para as comunidades; e

(c) na concepção dos bolsões de estacionamento coletivo, visando à maior proximidade e vigilância a partir das moradias, embora adotados em escala distinta do original. 


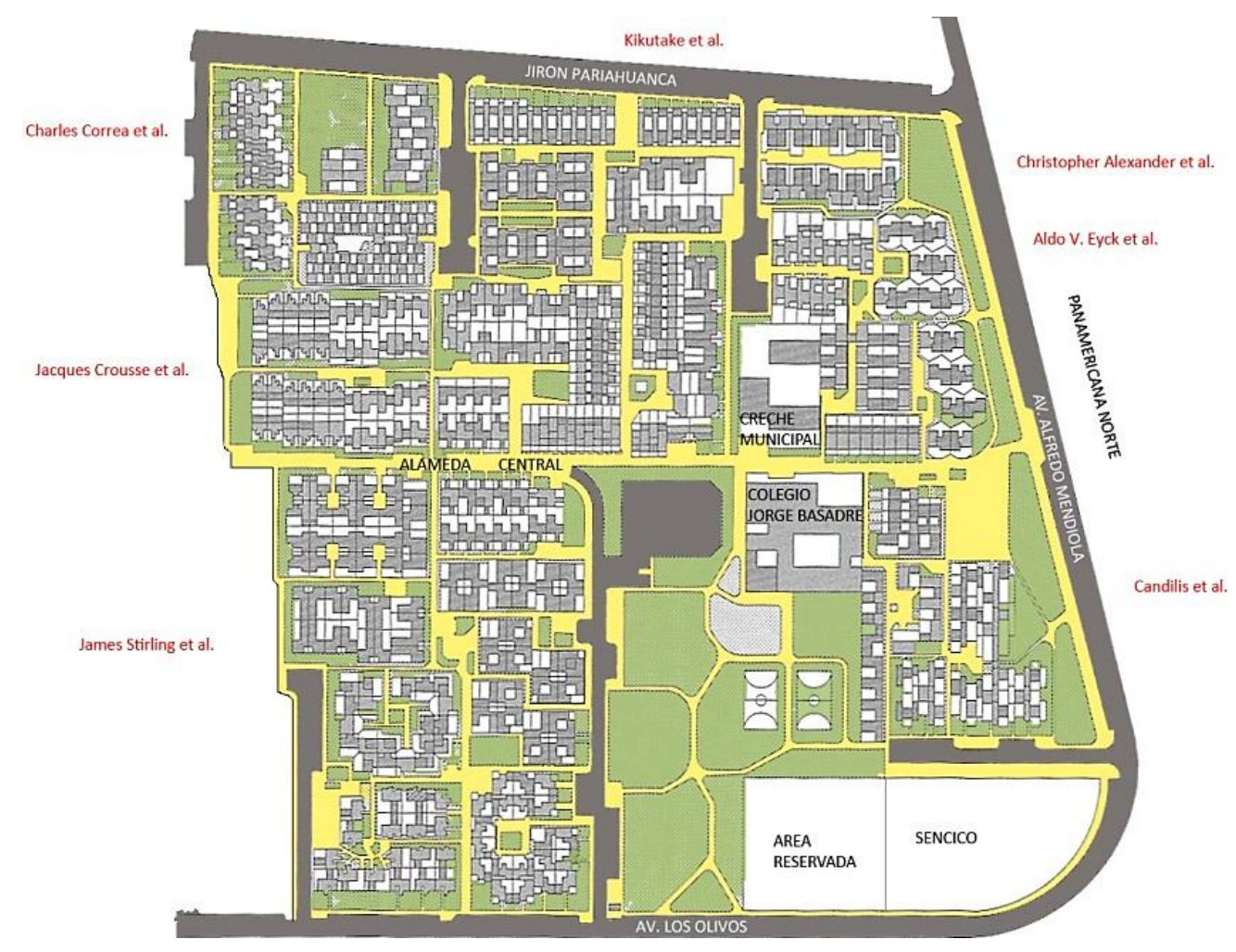

Figura 3 - PREVI implantado

Fonte: adaptado de Garcia-Huidobro, Torriti e Tugas (2008, p. 52).

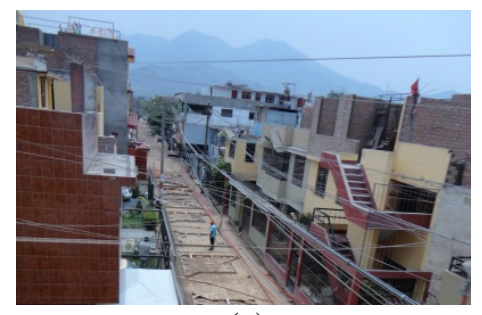

(a)

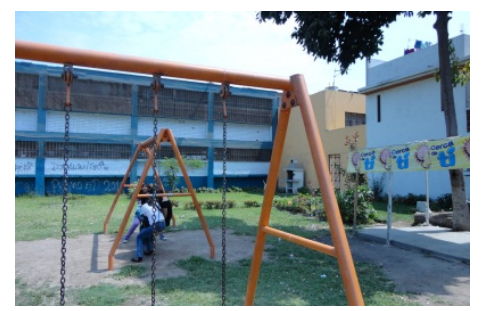

(d)

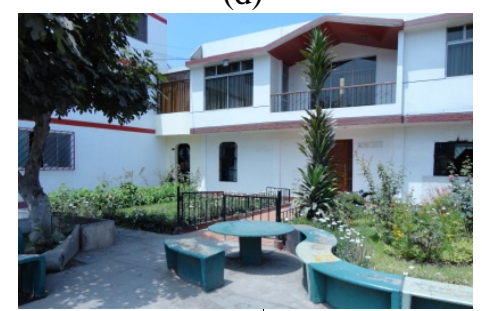

(g)

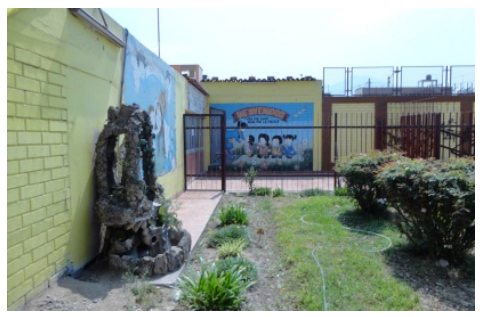

(b)

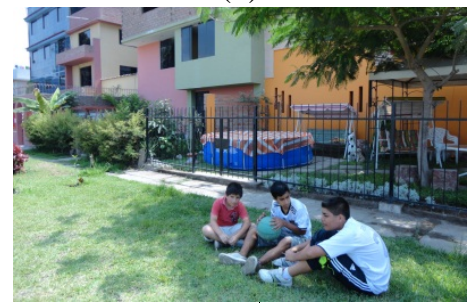

(e)

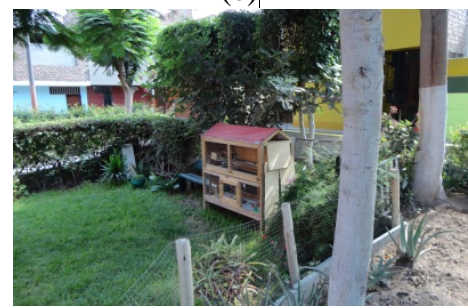

(h)

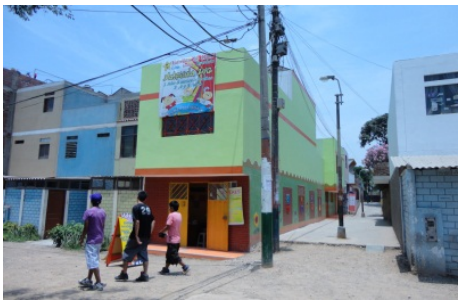

(c)

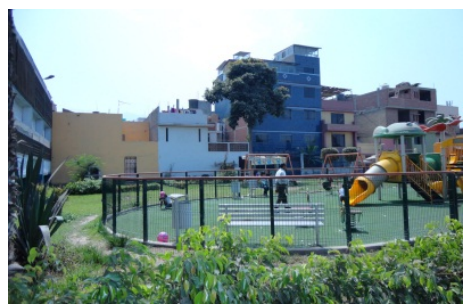

(f)

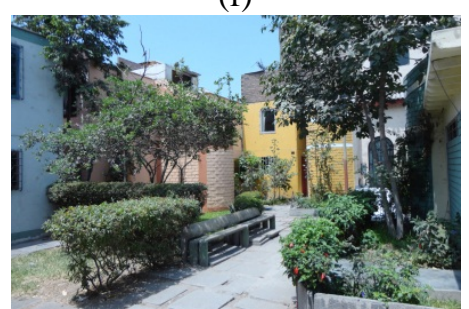

(i)

Figura 4 - Implantação do conjunto: (a) Alameda central (calçamento em manuenção); (b) e (c) Creches municipal e privada; (d), (e) e (f) Colégio J orge Basadre e respectivos espaços abertos; e (g), (h) e (i) Pequenas praças delimitadas por moradias 
O projeto implementado responde satisfatoriamente aos requisitos relacionados aos fatores ambientais, urbanísticos, de desenho urbano e de arquitetura estabelecidos pelo Concurso. Todavia, a inserção urbana de qualidade, incluindo a conjugação equilibrada entre os usos, dar-se-ia em parte pela localização próxima a indústrias e dependeria de sistema de transporte coletivo eficiente, ainda hoje não alcançado, conforme relato dos moradores antigos de diferentes quadras, na visita realizada. Esses moradores também descrevem a saturação da Escola Jorge Basadre e de seus parques, quadras esportivas e equipamentos de recreação de acesso livre, dada a necessidade crescente dos moradores dos assentamentos vizinhos menos favorecidos, fato que tem levado à depredação e degradação desses espaços e equipamentos de uso comum, que possuíam outro caráter nos primeiros anos do bairro. A densidade populacional do PREVI aumentou a olhos vistos, como também indicam os estudos de Tenicela (2002), García-Huidobro, Torriti e Tugas (2008) e Lucas, Salas e Barrionuevo (2012). Ao aumento de densidade soma-se a maior facilidade na aquisição de veículos individuais, que, em conjunto, sobrecarregam a demanda por vagas de estacionamento, também relacionada à já mencionada ineficiência do transporte coletivo. A tipologia geral de habitação compacta de baixa altura caracteriza o bairro, ainda que recentemente tenha ocorrido forte adensamento construtivo elevando o gabarito de altura.

\section{Exemplo das Quadras 16 e 17}

As Quadras 16 e 17 concentram as 14 moradias propostas pela equipe norte-americana, constituindo uma pequena vizinhança ladeada por jardins coletivos delimitados, cultivados e mantidos pelos próprios moradores, conforme informações fornecidas nas entrevistas. Um bolsão de estacionamento coletivo posiciona-se ao oeste das quadras (Figura 5), garantindo proximidade e possibilidade de vigilância a partir das moradias, conforme o parâmetro "estacionamento visível a partir da moradia”. Outro acesso dá-se por passeio, que se inicia na alameda central e passa por demarcação de entrada coletiva ao aproximar-se dos jardins. Caminhos de menor fluxo, ao norte e ao leste, também permitem o acesso. Todavia, portões em grades, usualmente trancados, visam dificultar a passagem de estranhos. Os moradores entrevistados relataram que a sensação de insegurança começou à época do grupo terrorista Sendero Luminoso, em que assassinatos ocorriam por toda a parte. A sensação perpetua-se devido ao adensamento das barriadas na vizinhança, cujos habitantes de menor poder aquisitivo utilizam-se dos equipamentos comunitários do PREVI, criando oportunidade para furtos leves. Lotes de duas frentes (Quadra 16) e de uma frente (Quadra 17) oferecem diferentes possibilidades no gradiente de privacidade no arranjo do conjunto: aqueles de duas frentes são mais expostos e adequados para o comércio e para a locação de cômodos, existentes em parte das casas.

Três variações tipológicas decorrem daquela tipologia habitacional original (Figura 2), sob um sistema construtivo adaptado para a pré-fabricação leve, que possibilita sua expansão e a flexibilidade dos espaços. As possibilidades de expansão horizontal ou vertical previstas situam-se na parte posterior. As variações tipológicas distribuem-se em 6 habitações de área maior (G: cerca de 120 $\mathrm{m}^{2}$ ), 5 habitações de área média (M: cerca de 80 $\mathrm{m}^{2}$ ) e 3 habitações de área menor (P: cerca de 75 $\mathrm{m}^{2}$ ), indicadas na Figura 5. Nenhuma delas foi contemplada com as varandas internas de $2 \mathrm{~m}$ originalmente previstas no térreo e piso superior, e somente a habitação do tipo $\mathrm{G}$ conta com os recuos na porta de entrada e projeção sobressalente do piso superior sobre o térreo (Figuras 6 e 7).

Cinco moradias nas Quadras 16 e 17 foram visitadas, sendo três da tipologia maior (Qd. 16-08, 17-05 e 17-06) e duas da tipologia menor (Qd. 1602 e 16-05). As entrevistas com os moradores indicam que ainda abrigam as famílias dos proprietários originais, que lá moram há 35 anos. A família da casa 16-02 optou por expandir a casa original para fins de locação. Todas as demais procederam às ampliações para melhor adequação das gerações de filhos que se casaram e tiveram netos. Originalmente, as famílias eram formadas, em média, por quatro pessoas e hoje se compõem de 4 a 9 pessoas. 


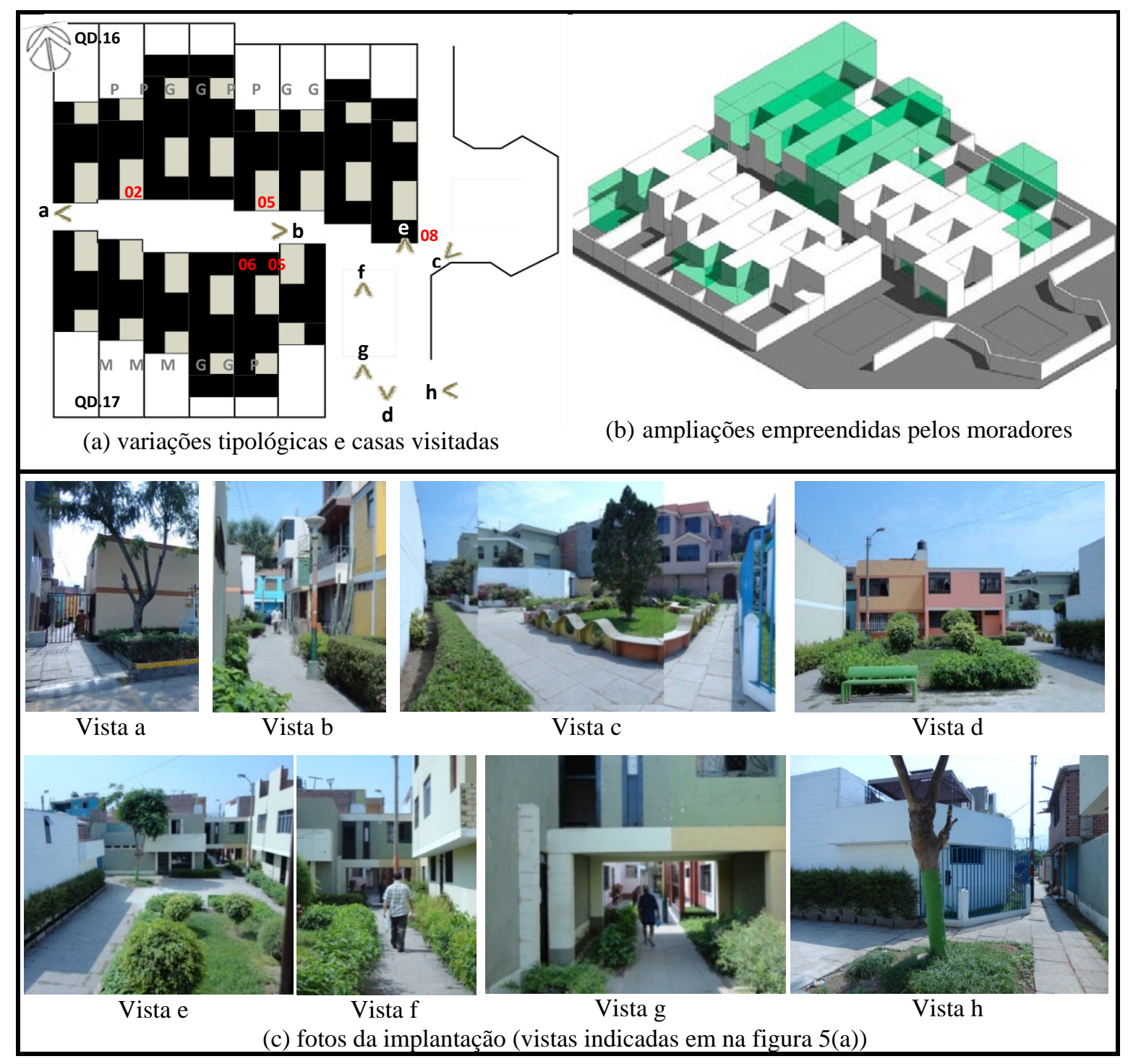

Figura 5 - Implantação das Quadras 16 e 17 

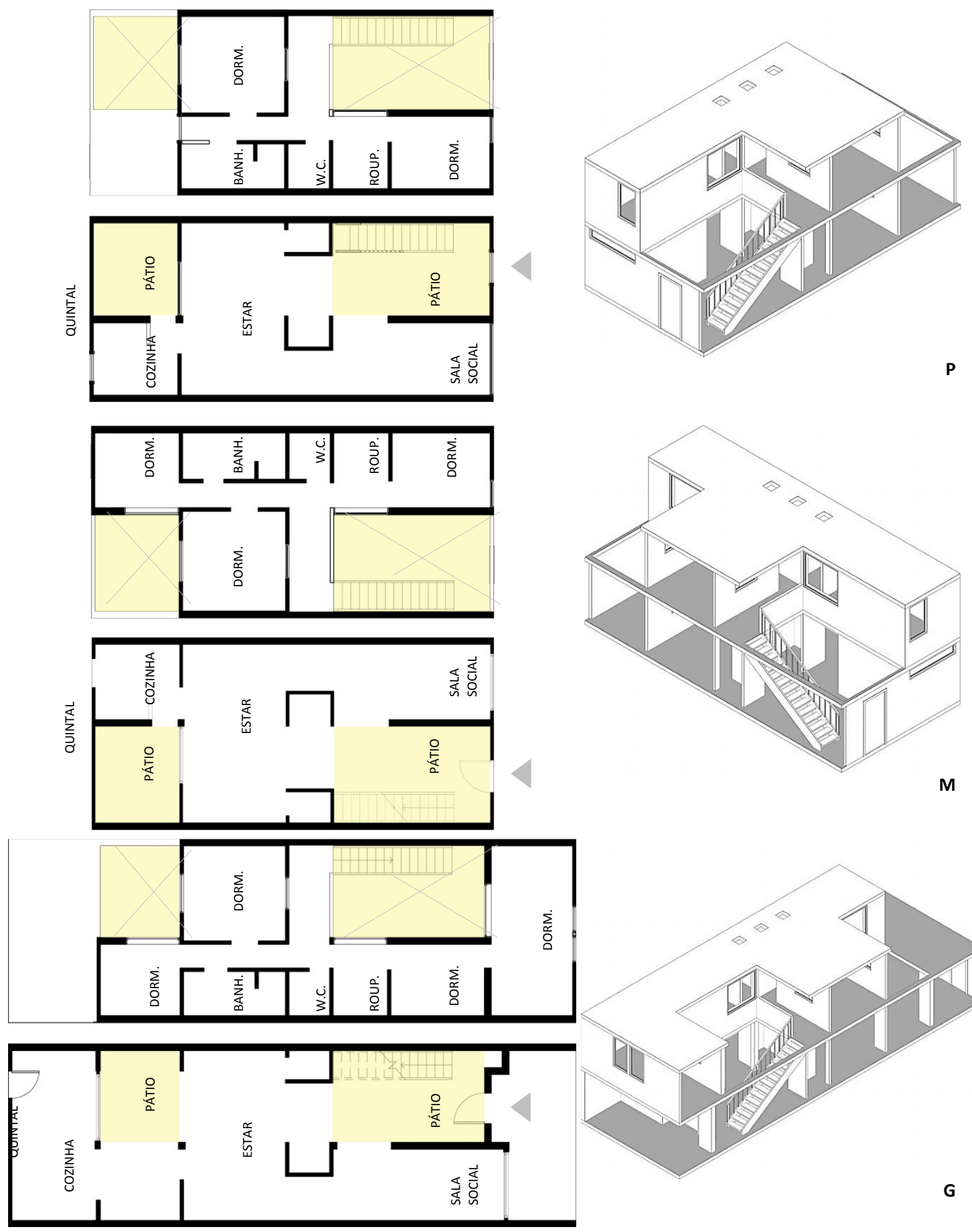

Figura 6 - Plantas-tipo térreo e superior e isométrica habitações construídas originais - tipos P, M e G 


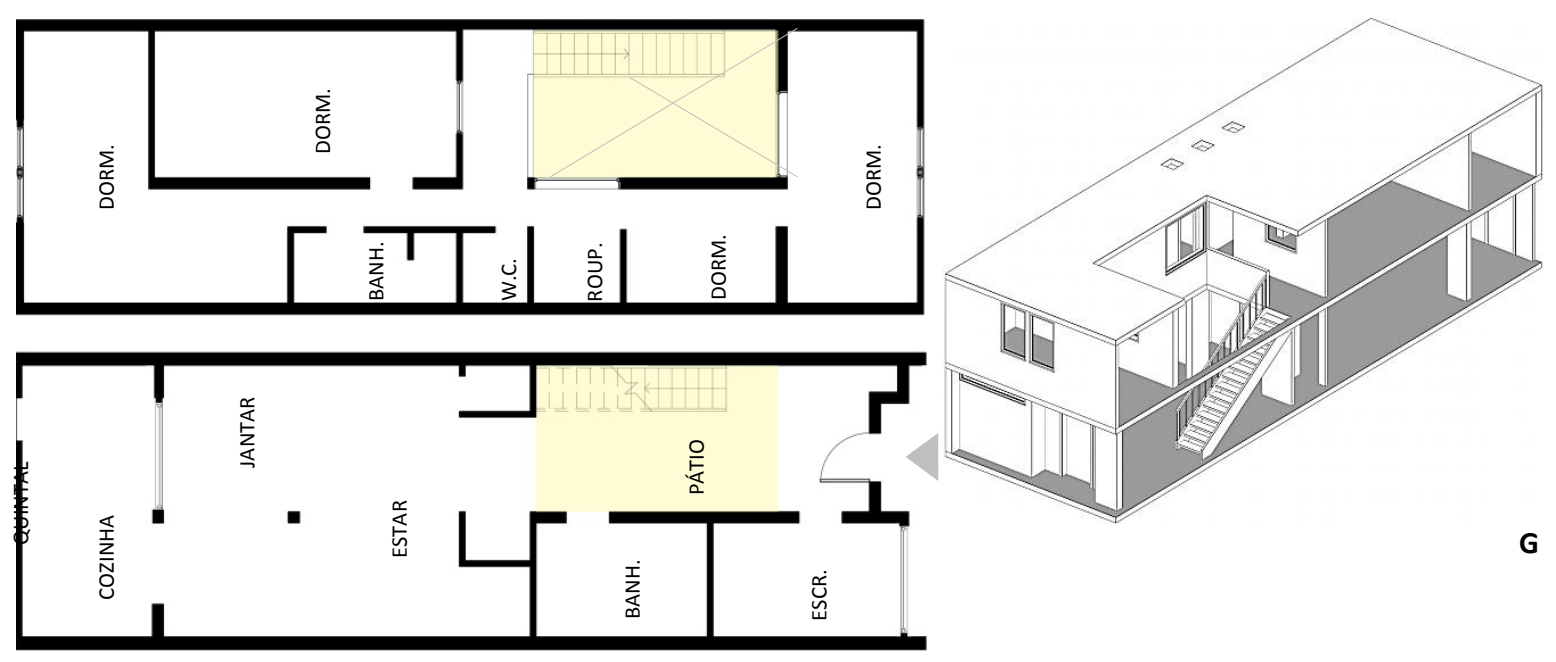

Figura 7 - Plantas-tipo térreo e superior e isométrica habitação tipo G - modificações típicas observadas em 2012

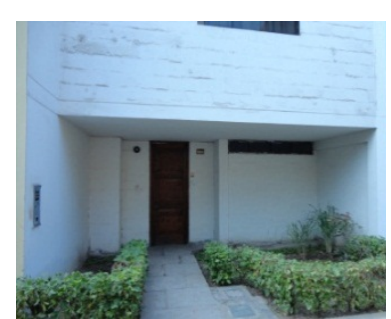

(a) 17-05

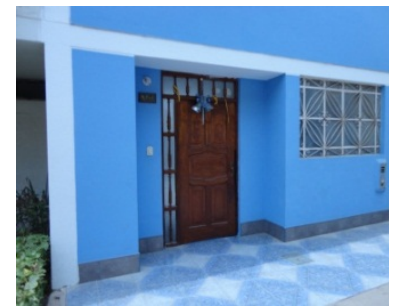

(b) 17-06

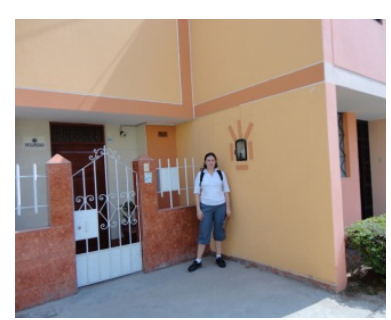

(c) 16-07

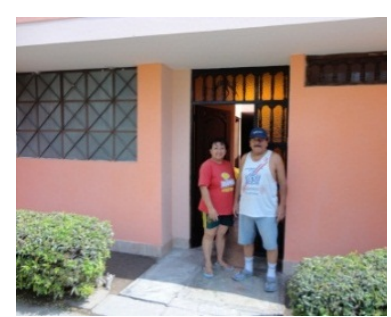

(d) $16-08$

Figura 8 - Entradas das habitações

As necessidades humanas de proteção e interação em relação ao passeio e à rua foram observadas por Alexander et al. (1969) devido a um período de vivência da equipe em moradias variadas nos bairros vizinhos ao local, à época do Concurso. Uma série de parâmetros constantes nos grupos orientação e forma, parte social e entrada e fachada - referem-se àquelas relações identificadas. Os parâmetros porta frontal recuada e transição na entrada dão início ao gradiente de intimidade, relacionado ao parâmetro casa estreita e comprida. Recuos na porta frontal foram previstos no projeto para demarcar e contribuir para a transição na entrada da moradia. Os recuos permanecem em muitas delas e têm sido também resgatados nos casos em que as expansões invadiram o recuo frontal, simulando o original. Nos exemplos da Figura 8, a habitação à esquerda (17-05) permanece original, e as demais ilustram o resgate dos recuos na porta frontal mesmo após expansão frontal da moradia.

Com relação ao pátio frontal, reconhece-se a relevância dos parâmetros pátios vivos e luz natural a partir de pátios em sobrados para a legibilidade e estímulos sensoriais em uma trama de luz e sombra, bem como para a garantia de luz natural a partir de duas faces e da ventilação cruzada para a qualidade ambiental (Figuras 9 e 10). Assim, o pátio frontal desempenha muitas funções simultaneamente: canaliza os ventos dominantes para os ambientes internos; contribui para uma transição na entrada através do contraste luminoso no percurso entre os ambientes, iniciando-se mais escuro na entrada (somente na tipologia maior), e a trama de luz e sombra, articulando o gradiente de intimidade da casa estreita e comprida (Figuras 2 e 9). Já o segundo pátio previsto no projeto entre a cozinha e a sala de jantar não se manteve, sendo eliminado para a ampliação de um dos dormitórios no piso superior (Figura 7). No piso térreo nota-se a maleabilidade da concepção arquitetônica e de seu sistema construtivo (Figura 9), o que permite a remoção de paredes internas e a obtenção de ambientes ainda mais espaçosos para os usos de estar e jantar, de modo mais ou menos integrado à cozinha, conforme desejado. 

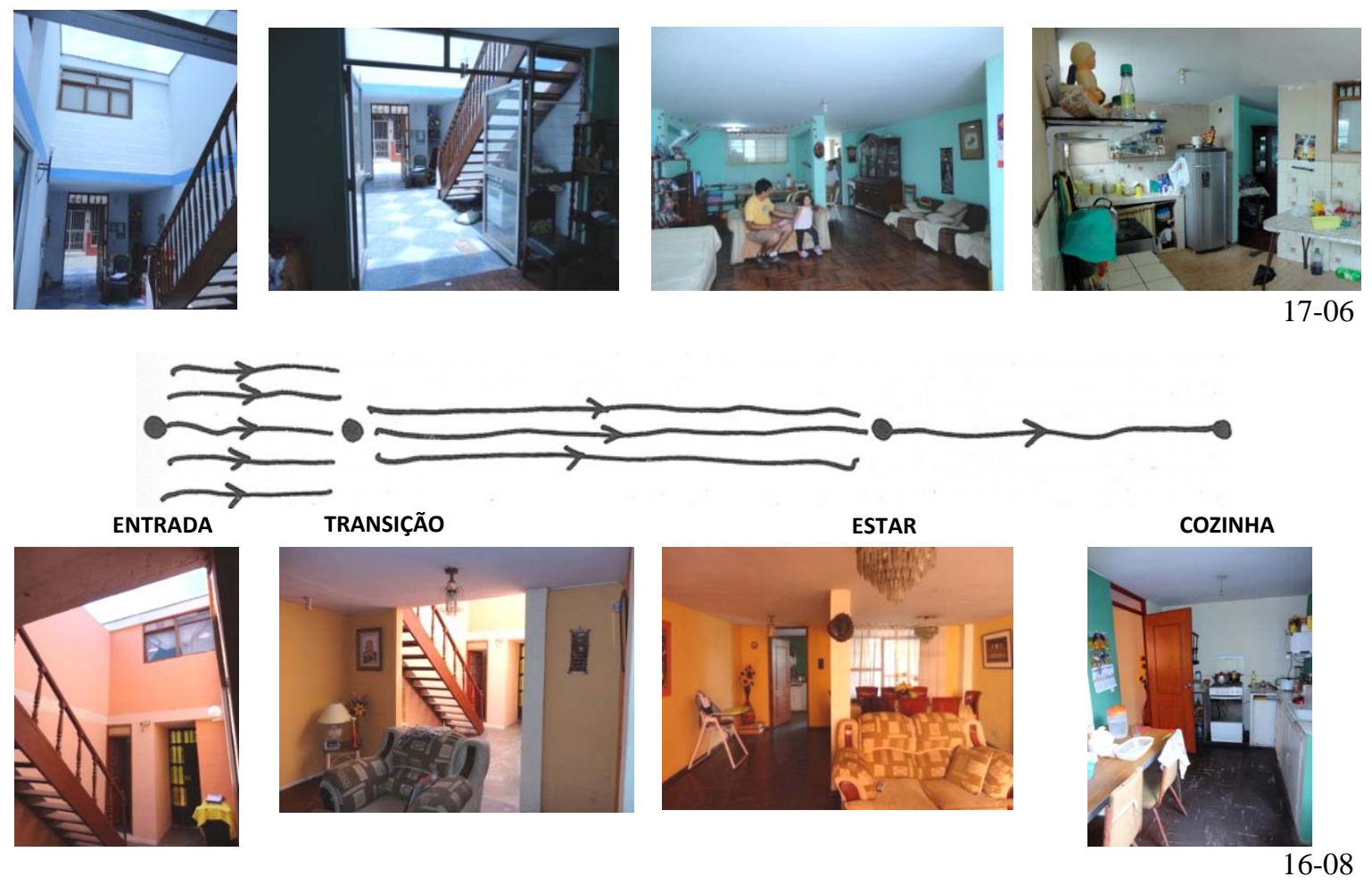

Figura 9 - Vistas internas a partir do pátio frontal e integração entre os ambientes no piso térreo (1706 e 16-08)

Fonte: croquis Gradiente de intimidade: adaptado de Alexander et al. (1969, p.128).

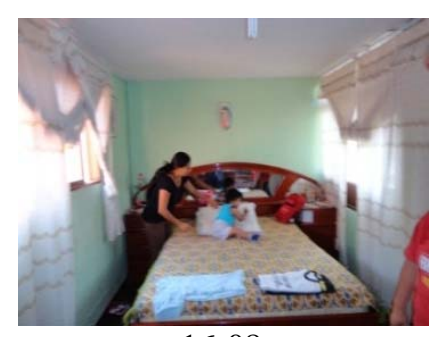

16-08

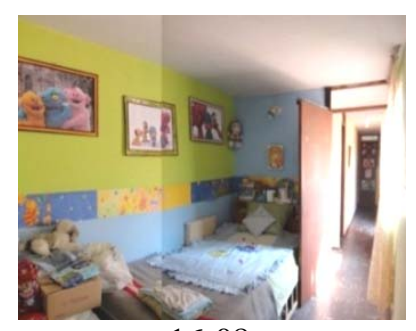

16-08

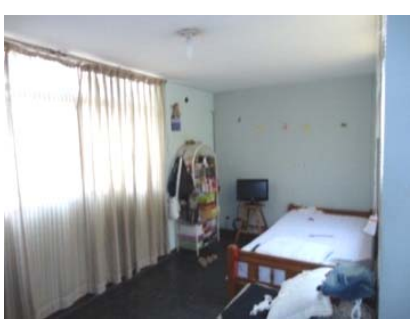

17-06

Figura 10 - Vista interna dos quartos no piso superior

\section{Lições para uma arquitetura de possibilidades a partir do PREVI}

Após 35 anos de ocupação, o PREVI constitui um verdadeiro bairro em que a moradia existe associada a outros usos, comércio, serviços e equipamentos comunitários. $\mathrm{O}$ parque, o colégio e a creche municipal configuram uma centralidade alimentada por caminhos em hierarquia, que desembocam na alameda central, com alto grau de legibilidade espacial. O projeto também possibilitou o surgimento espontâneo de outros equipamentos e serviços na alameda central e nas quadras. O traçado urbano é complexo, rico e promove a apropriação e o cuidado com o espaço público e coletivo, harmonizando-se às diferentes propostas arquitetônicas e construtivas. A maioria das intervenções nas moradias tem ocorrido em altura, não interferindo nos limites dos espaços coletivos e públicos e, portanto, não comprometendo o desempenho socioambiental desses espaços abertos. Na escala das habitações, não ocorreram programas de transferência de conhecimento para a capacitação dos moradores sobre as diferentes tipologias e sistemas construtivos, nem disponibilizada assistência técnica tanto para a garantia da segurança estrutural e da qualidade ambiental dos espaços internos como para evitar a descaracterização das quadras e do conjunto.

Ainda que merecedor de revisão no tocante à sustentabilidade de parte dos materiais sugeridos, 0 sistema construtivo proposto pela equipe norte- 
americana foi engenhoso quanto à combinação de estrutura em bambu e uso dos blocos intertravados, bem como a seu fácil manuseio, reparos e adaptabilidade pelos próprios moradores. Todavia, tal sistema não foi adotado devido ao uso de conectores não disponíveis no Peru (INSTITUTO..., 1979). Já Tenicela (2002) argumenta que foram as distâncias a serem percorridas àquela época, pelo bambu especificado, que tornaram a proposta economicamente inviável. Lucas, Salas e Barrionuevo (2012) consideram que as adaptações realizadas ao original enquadram o sistema executado na família tecnológica de maior aplicação no PREVI: a pré-fabricação leve ou racionalização construtiva, e constatam a afinidade entre as tecnologias usadas no PREVI e as demais técnicas empregadas na América Latina, baseadas na pré-fabricação racionalizada de pequenos elementos. A experiência leva a crer que há uma semente industrial que tenta (mas não consegue) arraigar-se, devido à realidade tecnológica e de mão de obra que move o mercado da construção desses países. Assim, muito embora haja variedade de tecnologias pré-fabricadas adotadas, as sucessivas transformações deram-se por meio do uso de técnicas construtivas tradicionais. Tenicela (2002) e Lucas, Salas e Barrionuevo (2012) relatam que teria colaborado para esse fato 0 descaso proposital das administrações posteriores por razões políticas, promovendo indiretamente a descaracterização do PREVI e das áreas contíguas.

$\mathrm{O}$ projeto da equipe norte-americana para o Concurso agrega como diferenciais a ênfase na diversidade de combinações de lotes e habitações e processos participativos de escolha dos lotes e da hierarquização das partes da moradia, porém não efetivados; os parâmetros relacionados ao atendimento das diferentes necessidades de proteção e convívio influenciaram o desenho urbano do PREVI implantado (Figura 5); os parâmetros na escala da moradia permanecem na amostra efetivamente construída (Figuras 8 a 10). Também se verifica a flexibilidade, sobretudo enquanto oportuniza adaptabilidade para a acomodação de usos ao longo dos 35 anos decorridos (Figuras 6 e 7).

A aprendizagem com o PREVI refletiu na proposta de instrumental de promoção de qualidade socioambiental em relação dinâmica com as abordagens investigadas neste trabalho. Os conceitos propostos são interdependentes:

(a) harmonizar-se ao lugar e aprimorá-lo significa estreitar a relação entre o ambiente construído e natural para reverter a atual tendência degenerativa de ocupação e uso territorial. Tal reconciliação requer o abrigo da biodiversidade e oportunidades para a vida em contínua adaptação, ou seja, a almejada capacidade adaptativa;

(b) priorizar a diversidade, em conjunto com políticas habitacionais que garantam o acesso aos serviços e o direito à cidade, é fundamental para evitar a segregação socioambiental nos territórios habitacionais e interage com as especificidades do lugar, dotando-o de significado e proporcionando a vivacidade urbana;

(c) estabelecer processos participativos contribui para o abrigo efetivo daquela diversidade, pois o envolvimento dos moradores pode ocorrer de maneiras diversas e nas diferentes etapas do projeto ao uso do ambiente construído, desde o estabelecimento do programa habitacional;

(d) atender às diferentes necessidades humanas de convívio e proteção inclui a interface com o desenho urbano, enfocando os arranjos espaciais e espaços resultantes e em articulação nas diferentes escalas da moradia na cidade; $\mathrm{e}$

(e) facilitar a flexibilidade, enquanto oportunidade de adaptabilidade aos usos e pessoas, viabiliza as modificações incrementais que podem assegurar o bom ajuste e a durabilidade, oferecendo o suporte à melhoria da qualidade de vida sem o comprometimento da qualidade ambiental, em interdependência com os demais conceitos.

A avaliação do PREVI implantado como um todo destaca um projeto que se ajusta ao lugar e aprimora-o a partir da cuidadosa consideração das características locais, incluindo a escolha da localização e fatores de impacto no conforto ambiental; prioriza a diversidade pela mescla de usos, oferta de diferentes faixas de custo, tipologias e oportunidades de adaptabilidade e expansão; atende às necessidades de convívio e proteção pela conformação e articulação dos espaços coletivos e públicos em hierarquia; prevê a flexibilidade de arranjos espaciais e de usos sociais para as diferentes fases de vida a partir de diversos elementos estruturantes e de espaços de múltiplo uso nas escalas da implantação e da moradia. Muito embora processos participativos não tenham sido formalmente PREVIstos, eles ocorrem pelas ações da associação dos moradores sobre a manutenção dos espaços coletivos e as reivindicações diante do poder municipal, conforme constatado na visita técnica: conquista da troca do piso da alameda central; intervenções individuais não comprometedoras do coletivo; e sinalização em praças diversas, valorizando os melhoramentos alcançados e o envolvimento dos moradores. O Quadro 2 apresenta e sintetiza o instrumental proposto com a aprendizagem do PREVI. 


\begin{tabular}{|c|c|c|}
\hline & CONCEITOS & $\begin{array}{l}\text { DESDOBRAMENTOS PARA ESCALAS DA CIDADE, VIZINHANÇA, } \\
\text { EDIFICAÇÃO, MORADIA }\end{array}$ \\
\hline 焉过 & $\begin{array}{l}\text { Estreitar relação com lugar e } \\
\text { garantir qualidade ambiental } \\
\text { através de projeto que adequa e } \\
\text { aprimora características locais. } \\
\text { Reconciliação entre ambiente } \\
\text { construído e natural requer } \\
\text { abrigo da biodiversidade e } \\
\text { oportunidades para a vida em } \\
\text { contínua adaptação. }\end{array}$ & $\begin{array}{l}\text { - Cidades compactas: articular localização, porte, densidade, capacidade } \\
\text { suporte, usos; priorizar TRANSPORTE COLETIVO e ENERGIA } \\
\text { HUMANA (caminhar e pedalar); oportunidades agricultura urbana } \\
\text { - Respeitar sítio e aprimorá-lo: CARACTERÍSTICAS LOCAIS (solo; } \\
\text { topografia; infraestrutura saneamento; iluminação natural; ventilação; } \\
\text { umidade do ar; aproveitamento água; vistas; vegetação; prevenção ruídos) e } \\
\text { PROCESSOS REGENERATIVOS inter-relacionados: redução consumo } \\
\text { energético; uso energia renovável; conforto ambiental; conservação água e } \\
\text { aproveitamento de resíduos; materiais locais e de baixa energia incorporada, } \\
\text { reuso } \\
\text { Promover percepção caráter e vocação do LUGAR, variedade de } \\
\text { ESTÍMULOS SENSORIAIS }\end{array}$ \\
\hline 突是 & $\begin{array}{l}\text { Diversidade social interage c/ } \\
\text { especificidades do lugar } \\
\text { contribuindo p/ dotar-lhe de } \\
\text { significado e identidade, garantir } \\
\text { vivacidade e evitar segregação } \\
\text { socioambiental. Mudanças } \\
\text { incrementais permitem } \\
\text { acomodar demandas variadas no } \\
\text { tempo. }\end{array}$ & $\begin{array}{l}\text { - Articular porte, densidade populacional e espacial e usos na perspectiva da } \\
\text { diversidade: MESCLAR USOS com PROGRAMAS de MORADIA variados } \\
\text { - Oferecer DIVERSIDADE TIPOLÓGICA; MODALIDADES } \\
\text { ADAPTATIVAS (expansão, compartimentação, melhoramento); de } \\
\text { PROCESSOS de CONSTRUÇÃO (autoconstrução, mutirão, empreitada); de } \\
\text { PROMOÇÃO (pública, privada, mista); na RELAÇÃO de POSSE }\end{array}$ \\
\hline 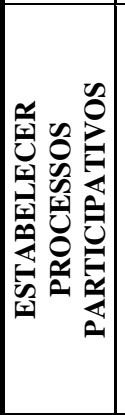 & $\begin{array}{l}\text { Promover processos } \\
\text { participativos nas diferentes } \\
\text { etapas desde o projeto ao uso do } \\
\text { ambiente construído p/ abrigo } \\
\text { efetivo da diversidade e } \\
\text { construção identidade. } \\
\text { Envolvimento permite } \\
\text { conciliação de valores e } \\
\text { negociação cotidiana das regras } \\
\text { de uso para que intervenções } \\
\text { individuais não ocorram em } \\
\text { detrimento do coletivo. }\end{array}$ & $\begin{array}{l}\text { - Processos ENVOLVIMENTO no PROJETO: possibilidades de ESCOLHA: } \\
\text { de LOTES para posicionamento no arranjo conjunto, implicações para forma } \\
\text { e extensão da habitação; de TIPOLOGIAS; de MODALIDADES } \\
\text { CONSTRUTIVAS; HIERARQUIZAÇÃO das PARTES da MORADIA } \\
\text { segundo necessidades particulares e capacidade aquisitiva, para processo } \\
\text { - Posterior de TRADUÇÃO de ESCOLHAS em projetos únicos } \\
\text { - Processos de ENVOLVIMENTO na CONSTRUÇÃO; na GESTÃO de USO } \\
\text { e MANUTENÇÃO dos espaçOs coletivos } \\
\text { - PROGRAMAS EDUCAÇÃO AMBIENTAL } \\
\text { PROGRAMAS de CAPACITAÇÃO e de APOIO TÉCNICO a modificações } \\
\text { futuras }\end{array}$ \\
\hline 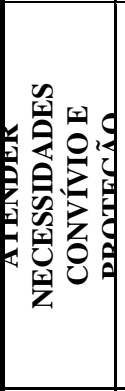 & $\begin{array}{l}\text { Promover percepção de sentido } \\
\text { de lugar e atendimento das } \\
\text { funções psicológicas de } \\
\text { orientação e identificação a } \\
\text { partir da conformação e } \\
\text { articulação entre arranjos } \\
\text { espaciais e espaços resultantes } \\
\text { nas escalas da moradia à cidade. } \\
\text { Proporcionar apropriação } \\
\text { positiva e acomodação de } \\
\text { demandas variadas no tempo. }\end{array}$ & $\begin{array}{l}\text { - Criar ESPAÇOS EXTERNOS POSITIVOS ao redor das edificações, } \\
\text { dotando-lhe de algum grau de conformação/delimitação (alas de edifícios, } \\
\text { vegetação, pergolados, arcadas, entre outros) } \\
\text { - Articular espaços externos coletivos e públicos em hierarquia para promover } \\
\text { LEGIBILIDADE e IDENTIDADE ESPACIAIS } \\
\text { - Estabelecer DIFERENTES GRAUS de ENVOLVIMENTO social e de } \\
\text { privacidade no arranjo do conjunto, distinguindo tipos de localização; } \\
\text { - Prever ambientes em relação mais direta com a rua, bem como criar espaços } \\
\text { de TRANSIÇÃO PÚBLICO-PRIVADA: conexão dentro-fora (fronteiras } \\
\text { permeáveis por arcadas, galerias, terraços e escadas de acesso abertas) } \\
\text { - TRANSIÇÃO NO ACESSO, porta frontal recuada e gradiente de intimidade }\end{array}$ \\
\hline 究 & $\begin{array}{l}\text { Ambiente construído mais } \\
\text { flexível viabiliza modificações } \\
\text { incrementais que asseguram } \\
\text { bom ajuste social e tecnológico. } \\
\text { Facilitar adaptabilidade } \\
\text { (flexibilidade de usos sociais no } \\
\text { tempo) e flexibilidade } \\
\text { relacionada à possibilidade de } \\
\text { diferentes arranjos espaciais e } \\
\text { construtivos. }\end{array}$ & $\begin{array}{l}\text { - Prever oportunidade de ADAPTABILIDADE: acomodação de usos, pessoas } \\
\text { e modos de vida variados: mescla de usos e ambientes multifuncionais; } \\
\text { edificação/habitação/ambientes passíveis de modificações pelos moradores: } \\
\text { prever possibilidade de ARRANJOS ESPACIAIS e CONSTRUTIVOS } \\
\text { distintos } \\
\text { - Elementos estruturantes IMPLANTAÇÃO: tipos de habitações (faces p/ } \\
\text { exterior) e tipos de edificações: modalidades MULTIFAMILIAR e } \\
\text { UNIFAMILIAR (tipos de acessos); localização e quantidade FACES no lote: } \\
\text { EXTENSÕES unifamiliares e multifamiliares; harmonizar conforto } \\
\text { ambiental, privacidade, contato c/ quintal, variação individual } \\
\text { - Elementos estruturantes de EDIFICAÇÕES e MORADIA: Tipo, dimensão, } \\
\text { posicionamento e combinações em sistemas construtivos; ADIÇÕES } \\
\text { VERTICAIS e ou HORIZONTAIS. OCUPAÇÃO com ou sem fechamento } \\
\text { via: Cobertura plana; Pátios internos; Circulação; Pés-direitos; Instalações e } \\
\text { áreas molhadas. Possibilidades COMBINAÇÃO e PARTIÇÃO entre } \\
\text { ambientes; ambientes de USO COMPARTILHADO }\end{array}$ \\
\hline
\end{tabular}

Quadro 2 - Instrumental para a promoção da capacidade adaptativa da habitação coletiva 


\section{Considerações finais}

As lições apreendidas a partir do PREVI e relacionadas às abordagens investigadas permitiram o aprimoramento da base teóricoconceitual de potencial humanizador e de sustentabilidade socioambiental vinculada ao projeto da habitação coletiva. $\mathrm{O}$ instrumental proposto apoia prática projetual para a promoção da capacidade adaptativa do ambiente habitacional, conduzindo a uma apropriação espacial positiva por uma diversidade de moradores e ações de melhoria de sua própria iniciativa, bem como em cooperação. O instrumental é composto de um conjunto de conceitos interdependentes, onde a conciliação de valores com o envolvimento comunitário se constituirão em importante estratégia para as intervenções individuais. Globalmente, tais conceitos agregam ao ambiente construído habitacional oportunidades para a vida em contínua mudança.

Editais de concursos públicos para habitação social no Brasil nos últimos tempos têm valorizado a provisão de moradias flexíveis e expansíveis para as modalidades unifamiliar e multifamiliar. Nessas iniciativas, apreende-se a preocupação maior com o barateamento e a escala da construção. Em boa parte, a produção promovida pelo Estado parece não reconhecer a importância da inserção e desenho urbanos, da conjugação moradia-trabalho e demais usos; não viabiliza o projeto participativo; e não requer projetos que incentivem iniciativas dos próprios moradores na melhoria de sua qualidade de vida e da sustentabilidade em suas variadas dimensões e escalas, incluindo a da cidade.

Assim, a iniciativa do concurso PREVI e o posterior fenômeno de apropriação dos espaços e intervenções merecem um olhar mais atento e abrangente, que supere interpretações tais como a de mostruário heterogêneo de tipologias ou a da consideração exclusiva de seu caráter de experimentação tecnológica. O caráter experimental reside também no contraponto ao paradigma moderno de edifícios de múltiplos pavimentos como solução padrão para habitação social, ao incetivar a habitação compacta de baixa altura em arranjo denso. Ressalta-se sobretudo a responsabilidade exemplar do edital quanto aos fatores ambientais, usos e tradições locais. O PREVI agrega lições para uma arquitetura de possibilidades que incentiva a interação entre as pessoas, suas atividades e o ambiente habitacional que as abriga. Espera-se que elas sirvam de inspiração para futuras iniciativas de projetos e concursos, especialmente para políticas públicas na área da habitação na América Latina.
A experiência do PREVI e as lições fornecidas de uma arquitetura adaptativa retomam e atualizam o conceito de habitação flexível e participativa, especialmente para sua incorporação no processo de projeto. Vislumbram-se outras perspectivas a partir da potencialidade proporcionada pelos sistemas generativos de projeto, ferramentas digitais integradas e sistemas de parâmetros que integrem e aprimorem os desempenhos social, cultural, programático, ambiental, material e estrutural (SALINGAROS, 2010). Nesse sentido, o potencial generativo pode alavancar outro posicionamento da arquitetura e sua materialidade, que se antecipa e ao mesmo tempo incorpora a capacidade de mutação inerente ao ser humano, possibilitando ao mesmo tempo atender a várias gerações no tempo.

\section{Referências}

ALEXANDER, C. et al. Houses Generated by Patterns. Berkeley: Center for Environmental Structure, 1969.

ANDRADE, L. S.; DUARTE, C. R. As Marcas da Imaginação na Habitação Urbana. In: DEL RIO, V. (Org.) Arquitetura: pesquisa \& projeto. Coleção PROARQ/ UFRJ. Rio de Janeiro: PROEditores, 1998. p. 161-169.

BARRIONUEVO, R.; JARA, C.; SANTOLALA, J. Publicación PREVI. Lima: Ministerio de Vivienda y Construcción del Perú, 1971.

BARROS, R. R. M. P. Habitação Coletiva: a inclusão de conceitos humanizadores no processo de projeto. Campinas, 2008. Tese (Doutorado em Engenharia Civil) - Faculdade de Engenharia Civil, Arquitetura e Urbanismo, Universidade Estadual de Campinas, Campinas, 2008.

BARROS, R. R. M. P.; PINA, S. A. M. G. Uma Abordagem de Inspiração Humanizadora Para o Projeto de Habitação Coletiva Mais Sustentável. Ambiente Construído, Porto Alegre, v. 10, n. 3, p. 121-135, jul./set. 2010.

BARROS, R. R. M. P.; PINA, S. A. M. G. LowIncome Multifamily Housing Design in São Paulo, Brazil: the need for humanising concepts. Journal Design Research, v. 9, n. 4, p. 301-320, 2011.

BAUMAN, Z. Confiança e Medo na Cidade. Tradução de E. Aguiar. Rio de Janeiro: Zahar, 2009.

BENEDIKT, M. (Ed.) Value 1. Austin: Center for American Architecture and Design, 1997. V. 10. (Center: Architecture and design in America). 
BENEDIKT, M. Human Needs and How Architecture Addresses Them. Austin, TX: University of Texas Press, 2008.

BOUDON, P. Lived-In Architecture: Le Corbusier's Pessac revisited. Massachusetts: The M.I.T. Press, 1972.

BRUNA, P. J. V. Os Primeiros Arquitetos Modernos: habitação social no Brasil 1930-1950. São Paulo: Edusp, 2010.

CANDIDATURE UNESCO DIFFÉRÉE. [Candidature]. Disponível em: $<$ http://lamachineahabiter.com/candidatureunesco/>. Acesso em: 11 abr. 2012.

CANDILIS, G.; JOSIC, A.; WOODS, S. PREVI/Lima, Low-Cost Housing Project. Architectural Design, n. 40, p. 187-205, apr. 1970.

COELHO, A. B.; CABRITA, A. R. Habitação Evolutiva e Adaptável: ITA 9. Lisboa: LNEC, 2009.

DU PLESSIS, C. Applying the Theoretical Framework of Ecological Resilience to the Promotion of Sustainability in the Urban SocialEcological System. In: SMART AND SUSTAINABLE BUILT ENVIRONMENTS, 4., São Paulo, 2012. Proceedings... São Paulo, 2012. p. 495-502.

FADDA, G.; JIRÓN, P. Calidad de Vida y Género em Sectores Populares: un estudio de caso en Santiago de Chile: sínesis final y conclusiones. Boletin del Instituto de la Vivienda, v. 16, n. 42, p. 105-138, mayo, 2001.

GARCÍA-HUIDOBRO, F.; TORRITI, D. T.; TUGAS, N. El Tiempo Construye! Time Builds! Barcelona: GG, 2008.

HABRAKEN, N. J. Supports: an alternative to mass housing. Mumbai: The Urban Int. Press, 1999.

HALL, S. A Identidade Cultural na PósModernidade. Rio de Janeiro: DP\&A, 2006.

HAMDI, N. Housing Wthout Houses: participation, flexibility, enablement. Exeter: Intermediate Technology Publications, 1991.

INSTITUTO DE INVESTIGACIÓN Y NORMALIZACIÓN DE LA VIVIENDA. PREVI 20 años después: resultados y conclusiones, edición de la Secretaría Ejecutiva del Programa de Actividades PREVI'88. Lima: ININVI, 1988.

INSTITUTO DE INVESTIGACIÓN Y NORMALIZACIÓN DE LA VIVIENDA. PREVI PP1: evaluacion comparativa. Lima: Ministerio de Vivienda y Construcción del Perú, 1979. v. 24.
JACOBS, J. The Death and Life of Great American Cities. New York: Random House, 1961.

KOWALTOWSKI, D. C. C. K.; PINA, S. A. M. G. Transformações de Casas Populares: uma avaliação. In: ENCONTRO NACIONAL SOBRE CONFORTO NO AMBIENTE CONSTRUÍDO, 3.; ENCONTRO LATINO-AMERICANO SOBRE CONFORTO NO AMBIENTE CONSTRUÍDO, 1., Gramado, 1995. Anais... Gramado: ANTAC, 1995.

LAND, P. The Experimental Housing Project (PREVI), Lima: antecedents and ideas. In: GARCÍA-HUIDOBRO, F.; TORRITI, D. T.; TUGAS, N. El Tiempo Construye! Time Builds! Barcelona: GG, 2008. p. 10-25.

LEFÈBVRE, H. Preface. In: BOUDON, P. LivedIn Architecture: Le Corbusier's Pessac revisited. Massachusetts: The MIT Press, 1972.

LEMOS, C. A.; SAMPAIO, M. R. A. Evolução Formal da Casa Popular Paulistana. São Paulo: FAU USP, 1976.

LERUP, L. Building the Unfinished: architecture and human action. Thousand Oaks: Sage Publications, 1977.

LUCAS, P.; SALAS, J.; BARRIONUEVO, R. Cuarenta Años del PREVI-LIMA: algunas enseñanzas para la industrialización de la vivienda de bajo coste en Latinoamérica. Informes de la Construcción, v. 64, 525, p. 51-62, ene./mar. 2012.

LYLE, J. T. Regenerative Design for Sustainable Development. New York: John Wiley \& Sons, 1994.

PINA, S. A. M. G. Habitar [n]a Cidade: um olhar para o território. IN: TASSARA, E. T.O. (Coord.)

Mudanças Climáticas e Mudanças

Socioambientais Globais: reflexões sobre alternativas de futuro. Brasília: UNESCO/IBECC, 2008. p.81-92.

PINA, S. A. M. G. et al. Transfer Process of SelfBuilt Houses in Environmental Protection Areas in the Region of Campinas. In: MIRA, R. G. et al. (Ed.). Culture, Housing, Space and Quality of Life. Aldershot, UK: Ashagate Publ, 2005. cap. 5, p. 41-58.

SALINGAROS, N. A. Twelve Lectures on Architecture: algorithmic sustainable design. Solingen: Umbau-Verlag, 2010.

SANTOS, C. N. F.; VOGEL, A. (Coords.). Quando a Rua Vira Casa: a apropriação de espaços de uso coletivo em um centro de bairro. 3 . ed. Rio de Janeiro: Finep/Ibam, 1985. 
SCHNEIDER, T.; TILL, J. Flexible Housing. Oxford: Architectural Press, 2007.

TALLEN, E. Design for Diversity: exploring socially mixed neighborhoods. Burlington, MA: Architectural Press, 2008.

TASCHNER, S. P.; MAUTNER, Y. Habitação da Pobreza: alternativas de moradia popular em São Paulo. Cadernos Prodeur. São Paulo: FAU-USP, 1982.

TENICELA, W. F. Arquitetura, Tecnologia e Cultura da Casa de Interesse Social no Peru.

Rio de Janeiro, 2002. Dissertação (Mestrado em Arquitetura) - Faculdade de Arquitetura e Urbanismo, Universidade Federal do Rio de Janeiro, Rio de Janeiro, 2002.
TURNER, J. F. C. Housing by People: towards autonomy in building environments. London: Marion Boyers, 1976.

\section{Agradecimentos}

As autoras agradecem à Fundação de Amparo à Pesquisa do Estado de São Paulo pelo apoio a esta pesquisa (bolsa PD processo 2010/13401-5); a Jorge Castillo Lozano pela hospitalidade e acompanhamento da visita técnica; aos demais moradores entrevistados do PREVI pelo acolhimento e permissão para conhecer suas moradias; aos professores Mauro C. O. Santos do PROARQ/FAU/UFRJ e Wilder F. Tenicela pelas informações e diálogos acerca do PREVI.

Revista Ambiente Construído

Associação Nacional de Tecnologia do Ambiente Construído

Av. Osvaldo Aranha, 99 - 3o andar, Centro

Porto Alegre - RS - Brasil

CEP $90035-190$

Telefone: +55 (51) 3308-4084

Fax: +55 (51) 3308-4054

www. seer.ufrgs. br/ ambienteconstruido

E-mail: ambienteconstruido@ufrgs.br 